\title{
Молодые врачи в городе и в селе: особенности профессиональной идентичности ${ }^{1}$
}

\author{
К.А. ГАЛКИН*
}

\begin{abstract}
*Константин Александрович Галкин - кандидат социологических наук, научный сотрудник, Социологический институт РАН - филиал Федерального научно-исследовательского социологического центра РАН; младший специалист-исследователь, факультет антропологии, АНООВО «Европейский университет в Санкт-Петербурге». Адрес: 190005, Санкт-Петербург, 7-я Красноармейская ул., д. 25/14; 191187; Санкт-Петербург, Гагаринская ул., д. 3. E-mail: Kgalkin1989@mail.ru
\end{abstract}

Цитирование: Галкин К.А. (2020) Молодые врачи в городе и в селе: особенности профессиональной идентичности // Мир России. Т. 29. № 3. С. 142-161. DOI: $10.17323 / 1811-038 X-2020-29-3-142-161$

В статье представлень результать исследования профессиональной идентичности молодых сельских и городских врачей. Медики как профессиональная группа имеют различные атрибуты профессиональной принадлежности: этические кодексы и стандарты, образовательную систему, одежду и сленг, ассоциации, ритуаль общения и иерархизированную структуру внутри самой профессии. В работе предпринята попытка взглянуть на профессиональную идентичность и врачебную профессию с точки зрения особенностей локаций, где практикуют медики, и представить их работу не с позиций функиионалистского взгляда на работу врача или общности города или села, а как индивидуальное видение своей принадлежности к профессии (конструирования профессиональной идентичности). Как показало исследование, профессия медика - во многом городская профессия, и идентичность врача, конструируемая в городе, связана с возможностями быть участником профессиональных сообществ и профессиональной жизни. Сельская местность с ее специфической сочиальной экологией и особой соччильной тканью обусловливает проблемы, связанные с потерей демаркационной линии между профессиональной идентичностью и идентичностью локальной. Это создает трудности в мотивации работь врачей и сложности в понимании индивидом своей профессиональной принадлежности. В перспективе решение проблем видится в создании профессиональных сообществ

1 Статья опубликована в рамках проекта НИУ ВШЭ по поддержке публикаций авторов российских образовательных и научных организаций «Университетское партнерство». 
молодых медиков в сельской местности и формировании пространств для маркирования профессиональной идентичности врачами в рамках досуговых практик в селе, а также в специальной подготовке медиков к работе в селе и ее многозадачности.

Ключевые слова: село, город, молодые врачи, профессиональная идентичность, сельская медицина, интеграция врачей в профессию, профессиональные проблемы

Вопрос разделения городского и сельского, с одной стороны, и социологической концептуализации города и села, с другой, как отдельных друг от друга полярных пространств до сих пор не получил однозначного решения. Классики, работавшие с определением сел и городов, убеждены, что городская жизнь и городской человек противопоставляются сельскому [Зиммель 2002, с. 2]. В. Зомбарт акцентировал внимание на разных экономических мирах города и села: так, город и отношения, существующие в нем, характеризуются капиталистическими ценностями, а для сельского жителя характерны докапиталистические ценности и «естественный человек» [Зомбарm 1994, с. 11]. Продолжая идеи демаркации, Ф. Теннис предлагал противопоставить социальные отношения людей в городских и сельских сообществах: для города характерны избирательная воля и общество со слабыми социальными связями (Gesellschaft), для села - общность (Gemeinschaft) и сущностная воля [Теннис 2002]. Основной акцент классиками делался на изучении отличий в социальных связях, существующих в городе и в селе [Пациорковский 2012, с. 26].

Этой точки зрения отчасти придерживался П.А. Сорокин, хотя его подход в разграничениях городского и сельского можно назвать более глубоким и обоснованным, ориентированным на конкретные маркеры. Так, П.А. Сорокин, много лет занимавшийся изучением особенностей городов и сел, выделял основные черты, по которым сельское отличается от городского. К ним относятся различия в занятости, средах обитания, размерах общин, плотности, однородности и неоднородности населения, социальной дифференциации и стратификации, мобильности и направленности миграционных потоков, взаимодействиях в городских и сельских сообществах [Sorokin, Zimmerman 1929, pp. 56-57; Пациорковский 2012, с. 27]. Полагаясь на классические демаркационные линии разделения городского и сельского, П.А. Сорокин вышел на более высокий уровень концептуализации этих пространств и приблизился к определению сельско-городского континуума (позже описанного в работах Е. Роджерса [Rogers 1998]), концепт которого предполагает изучение различий с учетом специфики городской и сельской жизни.

Исследования взаимодополняемости городов и сел приводят к появлению системного подхода в изучении этих социально-экономических образований, суть которого заключается в поиске отличий в самой среде или экологии расселения. В.В. Пациорковский предлагает рассматривать такие особенности, как близость к природе и возобновляемость сельских ресурсов, сплоченность жителей сел в качестве основных критериев, определяющих сельскость, в то время как для характеристики города им названы формирование зрелой, инфраструктурно насыщенной среды, последовательная утрата связей с природой и создание искусственного полиса, ориентированного на удобство горожан, рост числа 
рабочих мест и экономических свобод, а также свобода выбора занятий в профессиональной сфере [Пациорковский 2012, с. 28; Bupm 2005]. Принимая к сведению отличия в экологии города и села, в сельско-городском континууме попрежнему необходимо учитывать отличительные черты отношений, социальных связей и специфики коммуникаций. Городская жизнь, более формальная в межличностных коммуникациях, анонимизированная, не предполагает глубокого эмоционального вовлечения ее участников, в отличие от жизни сельской. Современные исследователи фокусируются на отличиях в конкретных социально-экономических отраслях и сферах деятельности жителей городов и сел, принимая во внимание тот факт, что в селах и городах могут отличаться условия работы и характеристики повседневной жизни индивидов [Woods 2012; Shucksmith 2011; Широкалова 2010; Гранберг 2015].

Среда городов и сел создается не только особенными природными ресурсами и различиями в организации пространств, но и самим сообществом, а также присутствующими в нем отношениями. При этом одним из типов отношений, наряду со сравнительно хорошо изученными социальными отношениями, выступают трудовые [Кодина 2014]. В связи с этим возникает вопрос: «Сохраняются ли отличия в трудовой сфере, где существуют единые стандарты и этические кодексы, регламентирующие профессиональную деятельность?». Интерес вызывают и представители конкретного профессионального сообщества внутри общности (общества) города или деревни как дополняющие социальные отношения и жизнь городского и сельского социумов.

Применительно к исследованиям профессий концепт «сообщества» использовался в работах структурных функционалистов, где под объединением профессионалов понимается подструктура большого общества, которая выполняет определенные функции и обладает профессиональной культурой, связанной с различными атрибутами профессии [Бочаров 2016, с. 83]. К таким признакам, как отмечает У. Гуд, относятся наличие профессиональной идентичности, общих и разделяемых ценностей сообщества, профессионального жаргона и лексикона, власти и социальных границ. Что же касается новых членов сообщества, то сначала они должны быть социализированы в рамках понимания ценностей, норм и знаний, существующих в профессии [Goode 1957, p. 194].

Профессия, таким образом, представляет собой наборы конститутивных признаков, которые включают этические нормы и ценности; профессиональный жаргон и сленг; автономность и экспертные знания; наличие образовательных институтов, учебных программ и квалификационных испытаний на право вести свою деятельность. Профессиональное сообщество и его описание в функционализме базируются на двух ключевых критериях: (1) на наличии социальных и моральных связей внутри сообщества; (2) на автономности, праве на экспертизу и par excellence (полный набор атрибутов, которые включает в себя понятие «профессия»).

Коллегиальность в общении и необходимость в сохранении профессиональной поддержки важны, и, как отмечает Р. Мертон, отсутствие этой поддержки и общих разделяемых ценностей и идей у представителей сообщества способно привести к распаду ассоциации [Merton 1958; Бочаров 2016, с. 84]. Описывая сообщества с этой позиции, исследователь подходит к пониманию профессиональной идентичности, трактуя ее как концепт, формирующийся на основании понимания 
принадлежности к профессиональному сообществу и индивидуальному маркированию смыслов профессии. При этом необходимо учитывать связку универсальной, эталонной профессиональной идентичности, основанной на общих нормах, ценностях и смыслах профессии, и идентичности профессиональной, локальной, определенной спецификой профессии в конкретном городе или стране.

В настоящее время активно проводятся исследования повседневности профессионалов, авторы которых используют феноменологический и социальноантропологический подходы [Becker, Geer, Hughes, Strauss 1977; Николаев 2012; Хьюз 2009; Ильин 2015]. В этих работах внимание акцентируется на изучении особенностей повседневной жизни представителей той или иной профессии и проникновения профессионального в повседневность специалистов. Важным в данном случае выступает интерес к самим специалистам, их видению и пониманию профессионального, которое может влиять на мотивацию продолжать работать или уйти из профессии и желание работать по профессии в конкретной локации. Такой подход позволяет исследователю быть внимательным к деталям, формирующим атрибуты сформированной профессии par excellence.

Вопросы конструирования профессиональной идентичности рассматриваются во многих российских и зарубежных работах по изучению профессий. В рамках этого направления изучается идентичность как вновь возникающих, так и классических профессий, которые характеризуются сформированной системой ценностей, этических кодексов, нюансов деятельности, наличием профессиональных атрибутов, например, специализированной одежды, выработанными способами общения с клиентами и пациентами [Marshall 1939; Абрамов 2013, с. 102; Щепанская 2003, с. 139-161; Щепанская 2011, с. 87; Романов, Ярская-Смирнова 2015].

Профессия врача определяется высокой степенью профессиональной автономии в регуляции работы благодаря наличию у него экспертных знаний [Freidson 2001, р. 127], которые обусловлены возможностью самостоятельно принимать решения, не зависеть при этом от государства и его институтов, а полагаться на советы коллег и профессионального сообщества и применять свои навыки в сочетании с предыдущим опытом [Jacob 2017; Петрова 2015; Чирикова 2013]. Экспертность заключается в знаниях прежде всего самих врачей, которые, например, должны ввиду проблем со связью (часто в сельских амбулаториях отсутствует интернет - прим. К.Г.) принимать решения самостоятельно, не надеясь на наставничество и коллегиальные советы старших товарищей. Особые этические кодексы медицинской профессии, регламентирующие деятельность врача, обязывающие, призывающие (во всяком случае, на страницах этих кодексов) к помощи любому и в любой ситуации, конструируют профессиональную автономию и определяют сущность профессии. Однако на практике зачастую можно видеть иную картину, когда государство или организация (больница, поликлиника) вмешиваются в работу врачей, диктуя свои нормы и правила, например, ограничивая временной регламент при работе с пациентами или создавая пакеты документов, которые необходимо заполнять после приема каждого пациента.

Еще одним малоизученным аспектом вмешательства в профессиональную автономию врачей выступает ситуация, когда среда и особая экология места способны ограничивать или улучшать работу профессионала и влиять на его видение своего профессионализма и обязанностей, на мотивацию к работе. Такими местами 
могут быть не только клиники и сельские амбулатории, но и само село или город как системы, образующие социальные отношения и структурирующие сферу занятости и деятельности [Галкин 2019]. Эти поселения сами по себе конструируют сельскую и городскую идентичность, определенную особенными контекстами социальных отношений, а также оказывают влияние на профессиональную автономию, ценности и наборы атрибутов. Локации выступают как ключевые компоненты профессиональной идентичности: например, имеются отличия в том, как конструируется идентичность в контексте длительной коммуникации врача и пациента в селе, вовлеченности врача в жизнь своих пациентов и проблемы села, как она проявляется в контексте анонимизированной и короткой коммуникации врачей с пациентами в городе, в рамках которой профессионал нацелен исключительно на выполнение своей задачи.

Таким образом, существуют как разграничения городской и сельской идентичностей, которые обусловлены неодинаковыми повседневными нюансами (коммуникацией, поведением, социальной тканью общности или общества), так и проникновение городской и сельской идентичностей в профессиональную сферу, где монополия на автономию медика и обладание атрибутами профессии могут быть скорректированы особенностями городской и сельской экологии и принятым в этих локациях позиционированием врача. Определяя профессиональную идентичность, необходимо учесть, что она конструируется не только атрибутами профессии, но и мотивацией врачей к работе и продолжению профессиональной деятельности в конкретной общности или обществе [Чирикова 2019].

В настоящей статье предпринята попытка проследить, как экологическая среда поселений влияет на структурные элементы профессиональной идентичности молодых врачей и на какие именно элементы профессиональной идентичности она влияет.

Эмпирической основой исследования стала полевая работа, проводившаяся в 2017-2018 гг. в Санкт-Петербурге и в Подпорожском и Лужском районах Ленинградской области. Изначально выбор данных регионов был сделан на основании предположения о том, что в федеральном городе (Санкт-Петербург) и в Лужском, Подпорожском районах Ленинградской области функционал врачей и специфика их коммуникации и взаимодействий с пациентами, коллегами, особенности проведения досуга весьма различаются, что в свою очередь обусловливает формирование индивидуального представления о профессии и конструирование профессиональной идентичности.

При выделении в работе исследовательских локаций важным было определение двух контрастных кейсов. Первый - город федерального значения (СанктПетербург) с населением свыше 1 млн жителей, наличием медицинских центров и больниц. Второй - села, поселки и деревни Лужского и Подпорожского районов, где молодые врачи работают в фельдшерско-акушерских пунктах (ФАПах) и амбулаториях ${ }^{2}$. Как правило, ФАПы состоят из одного врача общей практики, выполняющего функции терапевта, двоих фельдшеров и одной санитарки, которая также может исполнять функции медицинского регистратора. В амбулаториях больших поселков существуют кабинеты для забора анализов и аптечные киоски;

\footnotetext{
2 В двух исследуемых локациях интервью проводились с врачами, работающими в амбулаторно-поликлиническом учреждении (в городе) и в амбулатории или ФАП (в селах Ленинградской области).
} 
состав амбулатории включает двух врачей-терапевтов для взрослых, одного педиатра и одного фельдшера, аптечный киоск и кабинет для забора анализов.

Лужский и Подпорожский районы Ленинградской области удалены от СанктПетербурга более чем на 100 километров, что позволяет рассматривать их не как городские агломерации, а как отдельные районы, не связанные с городом. Всего было собрано 20 ( $\mathrm{N}=20)$ биографических интервью с молодыми врачами: 10 интервью с медиками, работающими в селах Ленинградской области, и 10 интервью с врачами Санкт-Петербурга. Возраст информантов (от 27 до 35 лет) был обусловлен спецификой и продолжительностью медицинского обучения; все они являлись врачами лечебных специальностей, работающими в государственных медицинских учреждениях в городе и селе.

Применяемый исследовательский метод - тематический анализ - позволил выделить в интервью ключевые сюжеты конструирования профессиональной идентичности.

\section{Молодые врачи в городе: особенности профессиональной идентичности}

Врачи, работающие в Санкт-Петербурге, считают, что крупный город представляет собой цеентр медицинны, под которым они понимают учреждение, предоставляющее большие возможности для профессиональной реализации в научной, технической, образовательной сферах, а также для включения в профессиональные сообщества и определения таким образом своей профессиональной автономии.

«Хорошо то, что у нас в городе сейчас активно развивается медицина различного профиля, и это притягивает врачей со всей России и из других стран работать здесь по специальности, чтобы повысить свой профессиональный уровень» (м., 30 лет, врач-гигиенист, СПб.).

При этом профессиональная автономия врачей в городе федерального значения ограничена иерархией, сложившейся в поликлинике. Принимая решение, молодому врачу необходимо советоваться со старшими коллегами и учитывать все правила и рекомендации административного контроля со стороны руководства. С одной стороны, такое общение необходимо с точки зрения соблюдения коллегиальности и актуальности получения советов опытных специалистов, но, с другой, оно ограничивает индивидуальную профессиональную автономию и выступает одним из элементов неудовлетворенности и снижения мотивации у молодых врачей.

«В медицинском деле без советов сложно обойтись, но хорошо, когда это советьрекомендации, а не надзирательство со стороны стариих коллег. Оно в принципе ничего нового не открывает и, скорее, даже ограничивает возможности общаться 
и разговаривать. Когда наступает «бумажная пора», а тебе необходимо идти и работать с пачиентами, это тоже очень сильно снижает твою мотивацию. Иногда видишь количество бумаг, оценишь время, которое нужно с ними возиться, все забрасываешь, идешь домой и думаешь: а зачем тебе это все нужно» (ж., 27 лет, эндокринолог, СПб.).

Как показало исследование, устойчивого баланса между «работой с бумагами» и работой с пациентами и у городских, и у сельских врачей не существует, однако это отражается на межличностных отношениях в коллективе, а также выступает одной из проблем, снижающей мотивацию к работе и провоцирующей желание перейти в другую сферу деятельности.

Еще одним фактором, снижающим мотивацию городских врачей, выступает осознание того, что полученное медицинское образование и имеющийся потенциал города, связанный с развитием новых медицинских центров и технологий, не всегда предоставляют достойные перспективы трудоустройства и реализации в карьере по специальности. Следовательно, образ города в данном случае встроен в конструирование профессиональной идентичности как образ образовательного иентра, т.е. места, где можно получить образование и интегрироваться в профессию, работая с врачами-профессионалами и экспертами внутри профессионального сообщества. Это усиливает профессиональную автономию, но проблемы трудоустройства и сложности с работой выступают факторами, снижающими мотивацию и уменьшающими желание врачей соотносить себя с профессией и продолжать работать по специальности.

С другой стороны, обстоятельство, которое способствует росту как профессиональной мотивации, так и желания конструировать свою идентичность и ассоциировать себя с профессией, - сам образ города, связанный с особыми «медицинскими местами», романтизирующими эту профессию. И здесь важными элементами выступают как здания, архитектура, организация пространств медицинских вузов, так и особые ассоциации, связанные с образом «петербургского врача» - профессионала, который своими знаниями и возможностями всегда защищал город от потрясений и перипетий времени.

«Да просто еще мой прадед был лейб-гвардии медиком, в ХІХ в., наверное, когда я рассматривал старинные семейные фотографии, когда мне отеи, тоже хирург из Мечки, рассказывал биографию деда, вот тогда уже захотелось быть как они и заниматься медициной. Поэтому я, наверно, себя определяю прежде всего не как просто врача, а как петербургского врача» (м., 25 лет, терапевт, СПб.).

Символизм «медицинских мест» города является одним из элементов в конструировании профессиональной идентичности и, с одной стороны, обозначает профессиональную автономию (ассоциируется со сложившимся профессиональным сообществом [Бочаров 2016]), а с другой, подчеркивает развитие и потенциал медицинской профессии, ее оформленность и традиции медицинских сообществ. 


\section{Работа с пациентами в городе}

Наиболее часто называемой в интервью проблемой при описании коммуникации с пациентами выступает скоротечность коммуникаций, которая связывается информантами с ритмом жизни города и количеством пациентов, а также с необходимостью долго работать с «бумагами» и выполнять «административную волокиту».

«Да, я быстро разговариваю с пациентами и считаю такую тактику наиболее удобной и правильной, не нужно впустую тратить время. Ты можешь достаточно быстро поставить диагноз, назначить лечение и перейти к следующему пациенту или к другим делам» (м., терапевт, 32 года, СПб.).

Такая короткая коммуникация с пациентами является признаком профессиональной автономии, одним из ключевых компонентов профессиональной идентичности, когда экспертность и оказание помощи по конкретной проблеме маркируют принадлежность к профессии и идентичность. Кратковременность приема при описании профессиональной идентичности выступает одной из особенностей в понимании ими своих обязанностей, поскольку руководители клиник и отделений выставляют временной регламент на работу с одним пациентом. Нередко такое поведение руководства выступает следствием неолиберального менеджерализма в профессии и вызывает протест у молодых врачей, которые говорили о необходимости использования гуманистической альтернативной модели взаимодействий с пациентами, о том, что хотели бы компенсировать недостаток внимания и заботы со стороны врача к пациенту, но сталкивались с правилами, ограничивающими и регламентирующими поведение специалистов на приеме [Темкина 2016; Бороздина 2016].

\section{Город и досуговые практики}

Подавляющее большинство молодых врачей, описывая свою повседневность, делали акцент на том, что особая экспертность и автономия требуют постоянного и безотрывного самосовершенствования, в том числе и свободного от работы или учебы времени. Одним из важных атрибутов, связанных с принадлежностью к профессии, выступают особые телесные практики, когда врачу необходимо доказывать преимущества здорового образа жизни (ЗОЖ), работы над своим телом, совершенствования и расширения физических нагрузок.

«Да, я как приехала в Питер, так сразу и начала бегать. И сейчас бегаю по утрам по набережной. Хорошо, что живу рядом с парком» (ж., 27 лет, кардиолог, СПб.). 
Конструирование принадлежности к профессии через практики поддержания здорового образа жизни связано как с необходимостью маркировать свою автономию в контексте работы над телом, так и с точки зрения возможностей большого города с различными ресурсами получения необходимых советов от фитнес-инструкторов и занятия спортом. С поддержанием ЗОЖ молодых врачей связано также спортивное наставничество - форма активизма, когда врач выступает тьютором и фитнес-экспертом и может обучать правильным навыкам здорового образа жизни большие группы людей. Особенными атрибутами конструирования профессиональной идентичности в городе в рамках досуговых практик становится оказание помощи молодыми врачами нуждающимся.

«В Питере я сейчас курирую одну из групп, которая занимается помощью. И поэтому для меня город - это, прежде всего, наверное, такая Мекка для активизма, где прекрасно можно реализовать свои планы, а помогать я люблю» (ж., 26 лет, терапевт, СПб.).

Экология и среда города, специфика его социальной жизни предоставляют врачам возможность рассказать о себе и делиться достоинствами своей профессии. Очень часто в нарративах интервью молодые врачи делали акцент именно на так называемых помогающих аспектах профессиональной деятельности, которые вписаны в пространство города. При этом в ходе исследования выяснилось, что позиции врачей относительно активизма и помогающих аспектов разделились. Те врачи, у которых в профессиональной деятельности существуют проблемы в работе с пациентами, кто столкнулся с их жалобами, убеждены, что именно профессиональный активизм и членство в профессиональных сообществах помогают им ощущать свою включенность в профессию и быть защищенными. То есть участие в деятельности профессиональных сообществ и в волонтерской деятельности задействует некий компенсаторный механизм, который может восполнить недостаточный профессионализм врачей и необходимость особой коммуникации с пациентами, например, предложение лекарств по настоянию фармацевтических компаний. Те же врачи, у кого нет проблем в общении с пациентами (в первую очередь это те, кто критиковали биомедицинскую модель общения и короткую коммуникацию), утверждали, что медикам необходимо принимать участие в волонтерских акциях и сообществах для передачи помогающих аспектов профессии не только на работе, но и в нерабочее время. Однако и для тех, и для других врачей важным выступает включенность в рамках активизма в сообщества, где становится возможным либо транслировать свою идентичность и профессиональную автономию в контексте помогающих практик, либо защищать профессиональную автономию в профессиональных ассоциациях.

Особенностью конструирования профессиональной идентичности врачей в городе является причастность к профессиональному сообществу, которая, наряду с символизмом города и традициями образовательной подготовки профессионалов, создает мотивацию продолжать работать по профессии, в то время как проблемы профессионального трудоустройства, вопросы иерархии и чрезмерного наставничества служат демотивирующими факторами для врачей. Маркирование 
профессиональной идентичности из-за недостаточной возможности официально выразить свою принадлежность профессии переходит на пространство досуговых практик, в рамках которых медики стараются отстоять свою профессиональную идентичность.

\title{
Молодые врачи в селе: работа и карьера
}

При описании работы в сельской местности молодые врачи старались маркировать профессиональную автономию, описывая свою деятельность в периферийных поселениях как экспертную. Эта особенность в работе сельского врача, с одной стороны, определяет профессиональную автономию - на основании понимания того, что врачу необходимо прежде всего доверять своим знаниям, а с другой, обусловливает снижение у молодых врачей мотивации к работе в селе. Нередко необходимость оперативного принятия решений вызывает у молодых профессионалов стресс из-за опасения совершить ошибку.

\begin{abstract}
«Здесь ты ощущаешь себя настоящим экспертом и очень хорошо понимаешь, как и что происходит, как развиваются различные болезни, потому что здесь ты один и, следовательно, должен понимать и принимать всю ответственность твоей профессии» (м., 32 года, врач общей практики, ЛО).
\end{abstract}

Для многих информантов мотивирующим фактором продолжения работы в сельской местности становится возможность получения необходимых средств («подъемных») и приобретения жилья по программе «Земский доктор»³. В целом программа оценивалась в интервью молодыми врачами позитивно (около половины опрошенных врачей), кроме того, большинство медиков говорили о серьезных проблемах с трудоустройством молодых профессионалов в городе. Однако содержание самой работы и ее условия оценивались негативно, и это было одной из причин, которые подталкивали к принятию решения отказаться от работы в периферийном поселении. Нередко информанты говорили, что работа в селе напоминала им труд медика XIX в., когда врач общей практики должен был разбираться во всех нюансах профессии, при этом не имея возможности досконально изучить особенности тех или иных болезней.

«Там (в городе - прим. К.Г.) я работала кардиологом и в большей степени была занята одним делом. Но здесь, в селе, приходится выполнять работу и специалиста по общим вопросам, и лечить, причем достаточно серьезно, сложные заболевания, в частности оказывать помощь при онкологических заболеваниях на нетерминальной стадии» (ж., 28 лет, терапевт, ЛО).

3 «Земский доктор»- программа, которая регламентируется законом № 336 Ф3 «Об обязательном медицинском страховании» и работает с 2012 г; рассчитана на привлечение молодых специалистов-врачей в сельские районы. 
Как правило, так описывали свой функционал молодые врачи, приехавшие из крупного города, ранее не имевшие опыта работы в сельской местности и взаимодействий с сельскими пациентами. Но при этом само по себе село выступает пространством, предоставляющим возможность применения имеющихся навыков и развития экспертности, хотя в будущем наиболее прогнозируемой траекторией таких «городских врачей» представляется возвращение в город.

«Просто сейчас нужно работать, но потом, конечно, я отсюда уеду, потому что ты вынужден выбирать или свежий воздух, или прогресс. И я, конечно, выбираю прогресс, но пока работаю, потому что нет другого места» (м., 29 лет, врач общей практики, ЛО).

Другую группу врачей составили информанты, родившиеся и выросшие в сельской местности: получив образование в городе, они изначально были ориентированы на работу в селе. Для них значимым атрибутом профессиональной идентичности стало особое представление о профессиональной автономии в контексте принадлежности к общности конкретного и часто родного села. Мотивирующим фактором выступает работа с пациентами - сельскими резидентами и людьми, которые, как правило, являются соседями и знакомыми. Но в таком случае, как об этом говорили некоторые из медиков, вернувшиеся в села, существует риск потери этической непредвзятости. Этот риск связан с тем, что, чем больше профессионал становится интегрированным в локальное сообщество села, тем сложнее ему справляться с мнением сельчан и ценностями локального сообщества, например, при лечении пациентов, которые нарушают принятые устои и традиции местного сообщества или не являются членами местного сообщества (как, например, мигранты или дачники, сезонно приезжающие в села).

Центральным сюжетом в нарративах городских врачей, переехавших работать в села, и врачей с сельским бэкграундом выступают неудовлетворенность условиями труда и необходимость выполнять административную работу, заполняя большое количество бланков, отчетов и форм от руки.

«Здесь вообще все очень сложно, в приниипе. То есть если в городе у тебя есть возможность что-то сделать электронно, то здесь ни баз, ничего нет изначально, и все, что ты делаешь, делаешь сам и от руки. Сам заполняешь необходимые документы, и все это затягивается часа на два и три, так и сидишь здесь после обеда u после обхода» (ж., 26 лет, врач общей практики, ЛО).

Сельские врачи отмечают знаковые нюансы своей работы, которые, прежде всего, определены особой ролью медика и взаимодействиями с пациентами и сельским сообществом. Врач здесь понимается, скорее, как эксперт-психолог, способный помочь и поддержать пациента. Именно транслирование заботы как о конкретном пациенте, так и об общности описывалось в нарративах врачей как залог успеха в работе. 


\section{Пациенты в селе: взаимодействие и коммуникация}

Особой чертой работы с пациентами в селе является необходимость лечить различные болезни и оперативно реагировать на жалобы пациентов. В отличие от города, где существует специализация врачей по отдельным направлениям и где пациенты обычно приходят с конкретными проблемами к врачу-специалисту, в селе к медикам могут обращаться с множеством вопросов. В данном случае применение широкого спектра навыков, несомненно, положительно влияет на развитие профессиональной компетентности, однако, с другой стороны, профессионализм и автономия (экспертность) ограничиваются отдаленностью от центра и затруднениями в лечении или постановке диагноза.

\footnotetext{
«Здесь все друг друга знают, и, следовательно, ты не можешь просто взять и "послать" пациента. Тебе нужно с ним общаться, потому что иначе как ты потом будешь ходить по селу?» (м., 35 лет, врач общей практики, ЛО).
}

При этом мнения пациентов о квалификации врачей были неоднородными: так, врача в селе могут воспринимать как психолога, которому можно было бы довериться и рассказать о своих проблемах, но, с другой стороны, перспективы серьезного лечения, равно как и квалификация сельского врача, ставятся под сомнение. Врач становится для односельчан, скорее, соседом или административным ресурсом в получении необходимых направлений на лечение, а для решения серьезных проблем жители села стараются обращаться в службу скорой помощи. Профессиональная идентичность сельских врачей при работе с пациентами, таким образом, становится более зависимой от мнения локального сообщества и от компетенций самого молодого врача, умения быстро сориентироваться в ситуации, его универсализма и правильности постановки диагноза. Ввиду отсутствия возможности очных консультаций с коллегами сельским медикам приходится советоваться с университетскими преподавателями или наставниками посредством интернета ${ }^{4}$.

Конструирование идентичности молодого врача в контексте взаимодействий и работы с сельскими пациентами определяется экспертностью медицинской профессии, когда врач понимается как специалист, который может оказать первую помощь, и особой мотивацией быть включенным в сообщество, которая в большей степени выражена у врачей с сельским бэкграундом. И в том и в другом случае профессиональная автономия играет весомую роль, поскольку как психологические, так и медицинские профессиональные знания врачей остаются частью профессии и залогом успеха.

\footnotetext{
4 Частой формой коммуникации с коллегами выступают личные переписка и общение в чатах, в рамках которых врачи могут получить экстренные рекомендации по лечению и назначению необходимых препаратов.
} 


\section{Село и досуговые практики}

Рассматривая досуговые практики в селе, предварительно следует обозначить их основное отличие от городских - ориентированность на локальное пространство и отсутствие возможностей развития различных направлений, которые предоставляет крупный город. Анализируя нарративы интервью, удалось выделить два основных вида досуговых практик, характерных для сельской местности: профессиональное онлайн-общение, расширение профессиональных навыков с помощью интернета и локальный активизм, который определен трансляцией профессиональных навыков врача, направленных на просветительскую деятельность в сельском сообществе 5 .

Вопросы, связанные с расширением профессиональных навыков молодых врачей в свободное от работы время, определяются ими как наиболее насущные. Вариантами получения новых знаний выступают общение в интернете с коллегами, бывшими однокурсниками и чтение публикаций по специальности, расширение кругозора через изучение новых подходов. С одной стороны, такое хобби способствует развитию профессиональной автономии и включенности молодых врачей в профессиональное сообщество, а с другой, позволяет «оставаться на связи» и получать необходимые советы. Важно, что подобное общение происходит в основном с врачами, практикующими в крупных городах, т.е. идентичность городского врача и города как пространства перспектив и профессиональной реализации по-прежнему значима для профессионализма сельских врачей. Город ассоциируется с медицинским сообществом, идентичность профессии и коллегиальность связаны с городом в контексте понимания атрибутов профессиональной деятельности и возможности быть виртуально включенным в сообщество.

«Нам, врачам, невозможно практиковать без постоянного общения с другими спечиалистами, и часто эти специалисты - либо твои однокурсники, либо твой институтский наставник, если у тебя с ним сложились хорошие отношения. Поэтому мы, врачи, постоянно должны быть на связи с кем-то, и это, конечно, определяет твое понимание как врача. То есть, если ты в сельском сообществе не можешь с кем-то, например, поговорить о свойствах нового лекарства, то идешь в интернет и там продолжаешь общение, и без этого никуда» (ж., 28 лет, терапевт, ЛО).

Другим вариантом проведения досуга, в рамках которого конструируется профессиональная идентичность, выступает волонтерская помощь сельчанам. В отличие от города, где волонтерство врачей носит в большей степени организованный характер, в селе подобная помощь является неформальной и в основном строится вокруг помощи сельскому сообществу. Для врачей, приехавших из города, волонтерская помощь - это еще и способ вынужденной интеграции в местное сообщество. Волонтерская помощь реализуется посредством проведения лекций о здоровом

\footnotetext{
5 Безусловно, в интервью присутствовало описание и других способов проведения досуга молодыми врачами, но в данном разделе я концентрируюсь на описании тех практик, на основании которых молодые врачи определяли не просто свой досуг, но и принадлежность к профессии.
} 
образе жизни, опасных болезнях и профилактике хронических заболеваний. Открытые лекции позволяют маркировать профессиональную автономию, во время лекции врачи делятся экспертной точкой зрения на проблемы с сельчанами. Это становится для медиков в селе наиболее важным для понимания своей идентичности.

«Отсюда пять километров онкологический больной живет, вот ему обычно и помогаю по дому. А так, здесь нет никаких фондов, и поэтому крайне сложно найти применение своим знаниям, поэтому вот и приходится так помогать» (м., 36 лет, врач общей практики, ЛО).

Следует отметить, что такая просветительская помощь и маркирование через нее профессиональной идентичности скорее характерны для врачей с сельским бэкграундом, чем для тех медиков, которые приехали работать в сельскую местность по программе «Земский доктор» и воспринимают работу в селе как временную.

Волонтерская помощь сельчанам позитивно воспринимается самим местным сообществом и выступает одним из способов интеграции в локальное сообщество через маркирование помогающих аспектов медицинской профессии и оказания помощи нуждающимся. Профессиональная автономия как важнейший элемент идентичности получает продолжение в социальной жизни и становится отличительной особенностью профессиональной деятельности врачей и обозначением принадлежности к медицинской профессии через понимание себя как специалиста, с эмпатией относящегося к людям. При этом такая автономия представляет собой, скорее, «вынужденную независимость», когда отсутствуют институциональная поддержка и помощь профессиональных сообществ и молодые врачи могут положиться только на сельское сообщество, которое поддерживает специалиста и становится едва не единственным каналом коммуникации в селе. Отсутствие организованной волонтерской поддержки в сельской местности делает подобную помощь уникальной и важной для периферийных поселений.

Итак, конструирование профессиональной идентичности молодых врачей, работающих в селах, можно охарактеризовать как балансирование между ценностями конкретной общности и локальной идентичностью, с одной стороны, и между идентичностью профессиональной и необходимостью ее сохранения, с другой. При этом мотивационная программа «Земский доктор», задействованная в Ленинградской области, способствует мотивации медиков и их желанию работать по профессии, однако важнейшей проблемой представляется отсутствие коллегиального общения, которое ввиду многозадачности работы врачей выступает фактором, снижающим мотивацию и желание продолжить работу в селе.

\section{Заключение}

Профессия врача неразрывно связана с городом и городским образом жизни. Поэтому в контексте конструирования профессиональной идентичности важными для врачей становятся поддержание связей, коллегиального общения и ощущение инте- 
грированности в профессиональное сообщество, которые ассоциируются с городом. Однако, несмотря на эти положительные моменты, сокращение рабочих мест для молодых врачей в городах, необходимость в четком иерархическом подчинении старшим коллегам вынуждают молодых медиков переезжать в периферийные поселения.

Мотивационные программы для сельских врачей наряду с предоставляемыми перспективами трудоустройства способствуют развитию автономии и осознанию ценности профессии, обусловленные продолжительным общением и взаимодействием с пациентами. При этом следует отметить, что недостающими атрибутами в конструировании идентичности врача в сельской местности выступают отсутствие коллегиальности, затруднение в получении необходимых консультаций у более опытных врачей и развитии новых знаний. Эта ситуация способствует потере этической непредвзятости, когда местное локальное сообщество села начинает диктовать врачам свои ценностные ориентиры, интегрируя специалиста в местную общность и особые отношения, существующие в социальной ткани села.

Значительной проблемой в данном случае выступает размывание демаркационной линии между идентичностью профессиональной и идентичностью места, которая отражается на качестве работы и характере взаимодействия с пациентами. Наиболее выраженной такая этическая субъективность является у молодых врачей с сельским бэкграундом - тех, кто после окончания медицинского вуза возвращается работать в сельскую местность. Потеря этической непредвзятости может выступать важным демотивирующим фактором и нарушать связи между другими факторами, что, безусловно, сказывается на мотивированности врачей работать по специальности.

Общение с коллегами, конструирование своей профессиональной идентичности в рамках не только профессиональных, но и досуговых практик, отсутствие обязательного следования четким иерархическим предписаниям и стандартам работы позволяют молодым врачам почувствовать себя частью профессии и стабильного профессионального сообщества. Эти настроения выражены через идентичность (как у городских, так и у сельских врачей) и маркирование принадлежности к профессии посредством особых практик и стиля поведения, которые могут либо ограничиваться экологией места, либо получать новые способы в выражении благодаря характерным социальным отношениям и различиям в организации социальной жизни в городах и селах [Laven, Wilkinson 2003; Вяткина 2012]. Важно, что в конструировании профессиональной идентичности врачей, помимо таких мотивационных факторов, как самореализация, материальные аспекты профессии и хорошая оснащенность места работы, немаловажную роль играют обозначение атрибутов профессии, перспектива конструирования своей профессиональной идентичности и ее трансляция в городскую или сельскую общность как в контексте работы, так и в рамках досуга.

Главной проблемой, снижающей мотивацию молодых врачей, выступают различия в условиях профессиональной деятельности в двух разных локациях. Общество города с его анонимизированностью жизни подпитывает нежелание молодых врачей проявлять заботу о пациентах, в то время как плотная социальная ткань сел демотивирует молодых врачей оставаться в профессии из-за слишком пристального внимания сельчан к медикам и попытки навязать врачу свои стандарты, особые ценности медицинской профессии, которые впоследствии могут негативно сказаться на идентичности. На поставленный в статье вопрос о возможности влияния экологии различных видов локаций на работу врачей, безусловно, 
дан утвердительный ответ. В будущем темами отдельных исследований должны стать глубинный анализ подобных влияний и проблемы, связанные с сепарацией профессиональной идентичности медика от идентичности локальной.

\section{Литература}

Абрамов Р.Н. (2013) Социология профессий и занятий в России: обзор текущей ситуации // Социологические исследования. № 1. С. 99-108.

Бороздина Е.А. (2016) Забота в родовспоможении: выгоды и издержки профессионалов // Журнал исследований социальной политики. Т. 14. № 4. С. 479-492.

Бочаров Т.Ю. (2016) Адвокатская профессия как сообщество практики // Социология власти. Т. 28. № 3. С. 80-114.

Вирт Л. (2005) Урбанизм как образ жизни // Вирт Л. Избранные работы по социологии. М.: ИНИОН РАН. С. 89-113.

Вяткина Н.Ю., Вахромеева А.Ю. (2012) Возрождение земской медицины: реалии и перспективы // Социология медицины. № 2. С. 38-40.

Галкин К.А. (2019) Когда работа не заканчивается. Профессиональные роли и отношение к помощи в нерабочее время у молодых сельских врачей // Мониторинг общественного мнения. № 3. С. 179-191. DOI: 10.14515/monitoring.2019.3.11

Гранберг Л. (2015) Структурные изменения в сельской местности России и Финляндии - сравнительный анализ двух различных типов общества // Мир России. Т. 24. № 3. С. 160-175.

Зиммель Г. (2002) Большие города и духовная жизнь // Логос. Т. 3. № 34. С. 1-12.

Зомбарт В. (1994) Буржуа. М.: Госиздат.

Ильин В.И. (2015) Профессия как индивидуальная жизненная колея: концептуализация категории // Журнал исследований социальной политики. Т. 13. № 4. С. 515-528.

Кодина И.Н. (2014) «Не хлебом единым...»: практики трудового поведения сельских жителей (случай села Парфеньево) // Лабиринт. № 3. С. 40-48.

Николаев В.Г. (2012) Социология занятий и профессий Эверетта Хьюза: Забытый интеллектуальный ресурс // Романов П.В., Ярская-Смирнова Е.Р. (ред.) Антропология профессий: Границы занятости в эпоху нестабильности. М.: Вариант, ЦСПГИ. С. 59-74.

Пациорковский В.В. (2012) Социология расселения как специальная социологическая теория // Социологические исследования. № 4. С. 25-34.

Петрова Л.Е. (2015) Профессиональный мир врача в современном российском обществе // Социология медицины. Т. 14. № 2. С. 53-57.

Романов П.В., Ярская-Смирнова Е.Р. (2015) Социология профессий: аналитические перспективы и методология исследований. М.: Вариант.

Темкина А.А. (2016) Оплачиваемая забота и безопасность: что продается и покупается в родильных домах? // Социология власти. Т. 28. № 1. С. 76-106.

Теннис Ф. (2002) Общность и общество. Основные понятия чистой социологии. СПб.: Владимир Даль.

Хьюз Э.Ч. (2009) Изготовление врача: общая формулировка идей и проблем // Журнал исследований социальной политики. Т. 7. № 3. С. 313-326.

Чирикова А.Е. (2013) Врачи как профессиональная группа: воспроизводство и поддержание врачебного профессионализма // Журнал исследований социальной политики. T. 11. № 3. С. 307-320.

Чирикова А.Е. (2019) О полимотивации врачей: уроки реформ // Мир России. Т. 28. № 3. C. 6-26.

Щепанская Т.Б. (2003) Антропология профессий // Журнал социологии и социальной антропологии. Т. 6. № 1. С. 139-162.

Щепанская Т.Б. (2011) Символизация повседневности и неформальный контроль в профессиональном сообществе // Романов П.В., Ярская-Смирнова Е.Р. (ред.) Антропология профессий, или Посторонним вход разрешен. М.: Вариант, ЦСПГИ. С. 85-113. 
Широкалова Г.С., Дерябина О.Н. (2010) Специалисты для села и село для специалистов // Социологические исследования. № 9. С. 26-39.

Becker H.S., Geer B., Hughes E.C., Strauss A.L. (1977) Boys in White: Student Culture in Medical School, New Brunswick, London: Transaction Publishers.

Freidson E. (2001) Professionalism, the Third Logic: On the Practice of Knowledge, Chicago: University of Chicago Press.

Goode W.J. (1957) Community within a Community: The Professions // American Sociological Review, vol. 22, no 2, pp. 194-200.

Jacob J.M. (2017) Doctors and Rules: A Sociology of Professional Values, London: Routledge.

Laven G., Wilkinson D. (2003) Rural Doctors and Rural Backgrounds: How Strong Is the Evidence? A Systematic Review // Australian Journal of Rural Health, vol. 11, no 6, pp. 277-284. DOI: 10.1111/j.1440-1584.2003.00534.x

Marshall T.H. (1939) The Recent History of Professionalism in Relation to Social Structure and Social Policy // Canadian Journal of Economics and Political Science / Revue Canadienne de Economiques et Science Politique, vol. 5, no 3, pp. 325-340. DOI: 10.2307/137036

Merton R. (1958) The Functions of the Professional Association // The American Journal of Nursing, vol. 58, no 1, pp. 50-54.

Rogers E.M., Burdge R.J., Korsching P.F., Donnermeyer J.F (1998) Social Change in Rural Society. Introduction to Rural Sociology, NJ: Prentice Hall.

Shucksmith M., Rønningen K. (2011) The Uplands after Neoliberalism? The Role of the Small Farm in Rural Sustainability // Journal of Rural Studies, vol. 27, no 3, pp. 275-287.

Sorokin P.A., Zimmerman C.C. (1929) Principles of Rural-Urban Sociology, New York: Henry Holt and Company.

Woods M. (2012) New Directions in Rural Studie? // Journal of Rural Studies, vol. 28, no 1, pp. 1-4.

\title{
Young Physicians in the City and in the Countryside: Features of Professional Identity
}

\author{
K. GALKIN*
}

\begin{abstract}
*Konstantin Galkin - PhD in Sociology, Researcher, Sociological Institute of RAS, a Branch of the Federal Center of Theoretical and Applied Sociology of the Russian Academy of Sciences; Junior Researcher, Faculty of Anthropology, European University at Saint Petersburg. Address: 25/14, 7 Krasnoarmejskaya St., Saint Petersburg, 190005, Russian Federation; 3, Gagarinskaya St., Saint Petersburg, 191187, Russian Federation. E-mail: Kgalkin1989@mail.ru
\end{abstract}

Citation: Galkin K. (2020) Young Physicians in the City and in the Countryside: Features of Professional Identity. Mir Rossii, vol. 29, no 3, pp. 142-161 (in Russian). DOI: 10.17323/1811-038X-2020-29-3-142-161

\section{Abstract}

Doctors have many identifiers of their profession: ethical codes and standards, an educational system, uniforms, professional language, professional associations, communication rituals and a hierarchical structure within the profession itself. But how 
does professional identity and the perceptions of the profession change in the context of environmental differences in settlements of different sizes? This study investigates the professional identity of young physicians in the locations where they practice, and presents professional activity not as a functionalist paradigm of society or the local community, but as the construction of their professional identity. The key components of professional identity considered are autonomy and motivational factors, which are the reference categories for their identity. The study is based on interviews with young physicians who work in outpatient clinics in cities or villages, or in rural dispensaries. The informants are aged from 27 to 32 years.

The study showed that being a doctor is in many ways an urban profession; the city and the identity of a physician are associated with membership of professional communities and professional life. Rural areas have a unique social ecology and special social relations which blurs the demarcation line between professional identity and place identity. This creates difficulties in motivating physicians and in understanding the individual's professional affiliation. A solution to the problem could be the creation of professional communities of young physicians in rural areas, the creation of opportunities and spaces for marking their professional identity in leisure activities, and special training for those working in rural areas.

Key words: sociology of professions, young physicians, city and village, professional identity, professional autonomy, symbolic borders of profession

\section{References}

Abramov R.N. (2013) Sotsiologiya professij i zanyatij v Rossii: obzor tekushchej situatsii [Sociology of Professions and Occupations in Russia: A Review of the Current Situation]. Sotsiologicheskie issledovaniya, no 1, pp. 99-108.

Becker H.S., Geer B., Hughes E.C., Strauss A.L. (1977) Boys in White: Student Culture in Medical School, New Brunswick, London: Transaction Publishers.

Bocharov T. (2016) Advokatskaya professiya kak soobshchestvo praktiki [Advocates' Profession as a Community of Practice]. Sociology of power, vol. 28, no 3, pp. 80-114.

Borozdina E.A. (2016) Zabota v rodovspomozhenii: vygody i izderzhki professionalov [Maternity Care: Benefits and Costs for Professionals]. Zhurnal issledovanij sotsial'noj politiki, vol. 14, no 4, pp. 479-492.

Chirikova A.E. (2013) Vrachi kak professional'naya gruppa: vosproizvodstvo i podderzhanie vrachebnogo professionalizma [Doctors as a Professional Group: Reproduction and Maintenance of Medical Professionalism]. Zhurnal issledovanij sotsial'noj politiki, vol. 11, no 3, pp. 307-320.

Chirikova A.E. (2019) O polimotivacii vrachej: uroki reform [On the Multiple Motivations of Physicians: Lessons from Reforms]. Mir Rossii, vol. 28, no 3, pp. 6-26.

Freidson E. (2001) Professionalism, the Third Logic: On the Practice of Knowledge, Chicago: University of Chicago Press.

Galkin K.A. (2019) Kogda rabota ne zakanchivaetsya. Professional'nye roli i otnoshenie k pomoshchi v nerabochee vremya u molodykh sel'skikh vrachej [When the Work Does not End. Professional Roles and Help Attitudes during Off-hours at Young Rural Doctors]. Monitoring obshchestvennogo mneniya, no 3, pp. 179-191. DOI: 10.14515/monitoring.2019.3.11

Goode W.J. (1957) Community within a Community: The Professions. American Sociological Review, vol. 22, no 2, pp. 194-200. 
Granberg L. (2015) Strukturnye izmeneniya v sel'skoj mestnosti Rossii i Finlyandii - sravnitel'nyj analiz dvukh razlichnykh tipov obshchestva [Structural Change in Finnish and Russian Countrysides: a Comparative Analysis of Two Different Types of Society] Mir Rossii, vol. 24, no 3, pp. 160-175.

Hughes E.Ch. (2009) Izgotovlenie vracha: obshchaya formulirovka idej i problem [The Making of a Physician - General Statement of Ideas and Problems]. Zhurnal issledovanij sotsial'noj politiki, vol. 7, no 3, pp. 313-326.

Il'in V.I. (2015) Professiya kak individual'naya zhiznennaya koleya: kontseptualizatsiya kategorii [Profession as an Individual Life Track: a Conceptualization]. Zhurnal issledovanij sotsial'noj politiki, vol. 13, no 4, pp. 515-528.

Jacob J.M. (2017) Doctors and Rules: A Sociology of Professional Values, London: Routledge.

Kodina I.N. (2014) «Ne khlebom edinym...»: praktiki trudovogo povedeniya sel'skikh zhitelej (sluchaj sela Parfen'evo) ["Not by Bread Alone ...": Practices of Labor Behavior of Rural Residents (Case of Parfenyevo Village)]. Labirint, no 3, pp. 40-48.

Laven G., Wilkinson D. (2003) Rural Doctors and Rural Backgrounds: How Strong Is the Evidence? A Systematic Review. Australian Journal of Rural Health, vol. 11, no 6, pp. 277-284. DOI: 10.1111/j.1440-1584.2003.00534.x

Marshall T.H. (1939) The Recent History of Professionalism in Relation to Social Structure and Social Policy. Canadian Journal of Economics and Political Science / Revue Canadienne de Economiques et Science Politique, vol. 5, no 3, pp. 325-340. DOI: 10.2307/137036

Merton R. (1958) The Functions of the Professional Association. The American Journal of Nursing, vol. 58, no 1, pp. 50-54.

Nikolaev V.G. (2012) Sotsiologiya zanyatij i professij Everetta Hughesa: Zabytyj intellektual'nyj resurs [Everett Hughes' Sociology of Occupations and Professions: an Outstanding Intellectual Resource]. Antropologiya professij: Granitsy zanyatosti $v$ epokhu nestabil'nosti [Anthropology of Professions: Employment Boundaries in the Era of Instability] (eds. Romanov P.V., Yarskaya-Smirnova E.R.), Moscow: Variant, CSPGI, pp. 59-74.

Patsiorkovskij V. V. (2012) Sotsiologiya rasseleniya kak spetsial'naya sotsiologicheskaya teoriya [Settlement Sociology as a Special Sociological Theory]. Sotsiologicheskie issledovaniya, no 4, pp. 25-34.

Petrova L.E. (2015) Professional'nyj mir vracha v sovremennom rossijskom obshchestve [The Professional World of a Doctor in Modern Russian Society]. Sotsiologiya meditsiny, vol. 14, no 2, pp. 53-57.

Rogers E.M., Burdge R.J., Korsching P.F., Donnermeyer J.F (1998) Social Change in Rural Society. Introduction to Rural Sociology, NJ: Prentice Hall.

Romanov P.V., Yarskaya-Smirnova E.R. (2015) Sotsiologiya professij: analiticheskie perspektivy $i$ metodologiya issledovanij [Sociology of Professions: Analytical Perspectives and Research Methodology], Moscow: Variant.

Shchepanskaya T.B. (2003) Antropologiya professij [Anthropology of Professions]. Zhurnal sotsiologii i sotsial'noj antropologii, vol. 6, no 1, pp. 139-162.

Shchepanskaya T.B. (2011) Simvolizatsiya povsednevnosti i neformal'nyj kontrol' v professional'nom soobshchestve [Symbolization of Everyday Life and Informal Control in the Professional Community]. Antropologiya professij, ili Postoronnim vkhod razreshen [Anthropology of Professions, or Unauthorized Entry Is Allowed] (eds. Romanov P.V., Yarskaya-Smirnova E.R.), Moscow: Variant, CSPGI, pp. 85-113.

Shirokalova G.S., Deryabina O.N. (2010) Spetsialisty dlya sela i selo dlya spetsialistov [Specialists for the Village and the Village for Specialists]. Sotsiologicheskie issledovaniya, no 9, pp. 26-39.

Shucksmith M., Rønningen K. (2011) The Uplands after Neoliberalism? The Role of the Small Farm in Rural Sustainability. Journal of Rural Studies, vol. 27, no 3, pp. 275-287.

Sombart W. (1994) Burzhua [Bourgeois], Moscow: Gosizdat.

Sorokin P.A., Zimmerman C.C. (1929) Principles of Rural-Urban Sociology, New York: Henry Holt and Company.

Temkina A.A. (2016) Oplachivaemaya zabota i bezopasnost': chto prodaetsya i pokupaetsya v rodil'nykh domakh? [Paid Care and Safety: What Is Sold and Bought in Maternity Hospitals?]. Sociology of Power, vol. 28, no 1, pp. 76-106. 
Toennies F. (2002) Obshchnost'i obshchestvo. Osnovnye ponyatiya chistoj sotsiologii [Community and Society. Basic Concepts of Pure Sociology], Saint Petersburg.: Vladimir Dal'.

Vyatkina N.Yu., Vakhromeeva A.Yu. (2012) Vozrozhdenie zemskoj meditsiny: realii i perspektivy [The Revival of Zemstvo Medicine: Realities and Prospects]. Sotsiologiya meditsiny, no 2, pp. 38-40.

Wirth L. (2005) Urbanizm kak obraz zhizni [Urbanism as a Way of Life]. Wirth L. Izbrannye raboty po sotsiologii [Selected Works in Sociology], Moscow: INION RAN, pp. 89-113.

Woods M. (2012) New Directions in Rural Studie? Journal of Rural Studies, vol. 28, no 1, pp. $1-4$.

Zimmel G. (2002) Bol'shie goroda i dukhovnaya zhizn' [Big Cities and Spiritual Life]. Logos, vol. 3, no 34, pp. 1-12. 